\title{
Before Corona and After Corona as New Global Milestones in The Theory and Practice of Consumer Behaviour: Evidence from Vending Industry
}

\author{
Jana Majerova ${ }^{1, *}$ and Lukas Vartiak $^{2}$ \\ ${ }^{1}$ University of Zilina, Faculty of Operation and Economics of Transport and Communications, \\ Department of Economics, Univerzitna 1, 01026 Zilina, Slovakia \\ ${ }^{2}$ Comenius University in Bratislava, Faculty of Social and Economic Sciences, Mlynske luhy 2893/4, \\ 82105 Bratislava, Slovakia
}

\begin{abstract}
.
Research background: In the light and shadow of contemporary global situation, Corona pandemic crisis can be established as new milestone in economic and managerial theory and practice. It has flew over national markets as black swan and it has totally destroyed so far formulated models and patterns. No one industry has stayed untouched.

Purpose of the article: The aim of this paper is to identify changes in consumer behaviour caused by Corona pandemic crisis in relevant industry of national economy.

Methods: The aim of this paper will be fulfilled by applying comparative analysis on the case study of vending industry provided on chronological basis. The reason for choosing this industry lies in the specifics of this industry - i.e. elimination of personal contact and nonstop functioning not only in closed but also in open air places. Thus, it can be expected that the impact of Corona pandemic crisis characterized by lockdown, social distancing and strict hygienic steps would be minimal in this case.

Findings \& Value added: It has been already stated that Corona pandemic crisis has a potential to modify so far formulated theoretical approaches to consumer behaviour. By providing own research, this fact has been proven. Based on these findings, it is possible to identify future trends in purchasing behaviour not only in case of chosen industry but also generally. These are mainly connected with the shift in perception of consumption and savings, the preference of cash less payment and the change in philosophy of personal alimentation.
\end{abstract}

Keywords: COVID-19; Corona pandemic crisis; black swan; consumer behaviour; vending industry

JEL Classification: F63; M21; M31; Z13

\footnotetext{
*Corresponding author: jana.majerova@.fpedas.uniza.sk
} 


\section{Introduction}

The global vending machine market size has been valued at USD 30.30 billion in 2018 and it has been expected to register a compound annual growth rate of $9.4 \%$ from 2019 to 2025 . Growing demand for on-the-go snacks, drinks, etc. due to a hectic lifestyle has been boosting product sales. The growth could also be attributed to the machine's ability to deliver goods quickly making it an extremely convenient option for consumers. Also, flexibility, in terms of location, i.e. indoor or outdoor coupled with the option to operate the machines 24/7 without any manual intervention has made them ideal for use in offices and commercial and public areas. Vending machines have been highly effective as they have helped to save labour costs, which has been also driving their demand. Technological innovations, such as face and voice recognition, interactive display system, and big data integration, making the product easier and more convenient to use would also have a positive impact on the demand. With such advancements, vending machines could deliver custom-made food items, salads, etc. apart from hot and cold beverages. Moreover, these machines have been considered as the most lucrative channel for sales at places like airports and train and bus stations due to increasing impulse purchases. However, strict regulations regarding the sales of unhealthy, junk food and tobacco products in public places and the majority of commercial spaces have been expected to restrain the growth of this market. Fixed product prices may also act as a major challenge for the industry. [1] According to consulting agency Fact.MR, the COVID-19 pandemic has adversely impacted the consumer goods industry with national and regional lockdowns disrupting production and supply chains. It is possible that the effect on food and beverage firms will be complex, affecting both the demand and supply equations. And unlike other sectors, a change in consumer habits have led to increased demand for several categories of consumer goods as well as shifting brand preferences. At the same time, manufacturers are determining how best to tackle possible disruptions to the supply chain and capacity constraints that may prevent them from meeting evolving customer needs. The vending machines market in particular also faced the impact of the COVID-19 crisis as demand was observed to dip in February and March compared to the demand in 2019 during those months. The decreasing demand of Vending Machines in 2020 can be understood under three scenarios: positive, pessimistic and probabilistic. Under the optimistic scenario, the global vending machines market is expected to decrease in the first, second and third quarter of 2020 under the COVID-19's strong impact, and demand may pick-up from the fourth quarter. On the other hand, under the probabilistic scenario, the market is expected to remain under doldrums until the end of the second quarter, affecting the sales of vending machines. Under the pessimistic scenario, demand is not anticipated to gain traction until after the first quarter of 2021. [2] Amid the COVID-19 crisis, the global market for Vending Machines estimated at US $\$ 134.4$ Billion in the year 2020, is projected to reach a revised size of US\$146.6 Billion by 2027 , growing at a compound annual growth rate of $1.3 \%$ over the analysis period 2020 2027 . Beverage, one of the segments analysed in the report, is projected to grow at a $1.7 \%$ compound annual growth rate to reach US $\$ 88.6$ Billion by the end of the analysis period. After an early analysis of the business implications of the pandemic and its induced economic crisis, growth in the Food segment is readjusted to a revised 1\% compound annual growth rate for the next 7-year period. This segment currently accounts for a $16.9 \%$ share of the global Vending Machines market. [3] In accordance with above mentioned, it can be stated that the COVID-19 crisis has globally caused significant changes in vending industry. However, there is still lack of scientific papers which would be focused on this specific issue. In details, nowadays, there is the main attention paid to the impact of the crisis on tourism and main manufacturing and service industries. [4, 5] 


\section{Theoretical background}

The birth of the vending machine as we now know it can be dated back to 1898, when passengers mounting the stairs to board New York's elevated trains first saw Tutti Frutti gum machines waiting for them on the platforms. The Pan American Exposition in 1901 introduced bulk vending machines that sold a measured amount of peanuts for a penny. In 1902, in Philadelphia, the Horn \& Hardart Baking Company opened the first Automat. In 1908 a machine that dispensed water in paper cups was introduced by the Public Cup Vendor Company of New York (later Dixie Cup). Prior to the 1920s, marketers of vending machines and the products they vended were one and the same. The industry bifurcated into manufacturers of consumables and vending machine manufacturers/operators with the introduction of machines that sold multiple kinds of products - packaged candy and lighter fluid in the same machine, or several types of candy. About the same time three types of cigarette machines were introduced. In the decade after World War II many small companies entered the industry with many design improvements. Coin mechanisms in particular became more sophisticated. In the late 1950s and early 1960s machines with electromechanical units began to appear. The 1960s is regarded by many as the golden age of the vending machine industry. Vending machines were a staple of the American workplace, and the vending industry benefited from a booming industrial sector. During this period prices were relatively stable, and most products could be purchased with a single coin. The economic climate of the following decade was less hospitable. The inflation of the 1970s made vending machines inconvenient, and there was also a shrinking in the manufacturing labour force where a large proportion of vending machine consumers were found. However, the product mix did change during this period, as bagged snacks began to grow in popularity at the expense of candy. The helical-feed glass-front candy/snack machine, which subsequently became the industry standard, also was introduced in the 1970s. The spread of microprocessors has since transformed the design and function of vending machines. Microprocessors made it much easier to design machines that offered multiple prices and an ever-widening product selection, expanding to include a wide variety of snacks, frozen foods, microwavable food, diet and low-fat foods, and healthy foods such as yogurt. Classical internal segmentation of vending market lies in product specialization. However, there are also others points of view beside this approach - character of application, payment mode and region are the most important ones. [6]

Based on the application, the vending machine market is segmented into commercial places, offices, public places, and others. Office application accounts for the largest market share and will be the fastest-growing segment over the forecasted period. Growing corporate and manufacturing sectors across the globe are the key factor driving product demand. Vending machines are widely used in offices to save space and costs and to maintain cleanliness. Commercial places application is also expected to have significant growth over the forecasted period owing to a rising number of commercial projects across the globe. These machines are widely used in hotels, clubs, colleges, hospitals, etc. [3]

Based on payment mode, the market is segmented into cash and cashless. Cash payment mode is estimated to be the largest segment over the forecasted period as the majority of the existing vending machines have cash as the only payment option as installation of devices featuring cashless options is relatively expensive. However, variable pricing fails in vending machines with cash as payment mode acts as a major restraining factor for the segment growth. Thus, the cashless payment mode segment is estimated to witness the fastest compound annual growth rate over the forecasted period. Also, many manufactures are partnering with several payment service providers to meet the growing demand for cashless payment options. For instance, American Food and Vending formed a partnership with PayRange to install contactless payment mode on their vending machines. [1] 
North America is estimated to be the largest regional market over the forecasted period due to factors, such as changing lifestyles and high demand for Ready-to-Eat (RTE) meals. On the other hand, Asia Pacific is estimated to be the fastest-growing region from 2019 to 2025. Japan is the most lucrative country in the regional market. [2]

However, consumers are deeply concerned about the impact of COVID-19, both from a health and economic perspective. [7] People are responding in a variety of ways and have differing attitudes, behaviours and purchasing habits. People across the globe are afraid as they strive to adapt to a new normal. Fear is running high as individuals contemplate what this crisis means for them, but more significantly, what it means for their families and friends, and society at large. [8] Consumers are responding to the crisis in a variety of ways. Some feel anxious and worried, fueling panic-buying of staples and hygiene products. At the other extreme, some consumers remain indifferent to the pandemic and are continuing their business as usual, despite recommendations from government and health professionals. $[9,10]$

According to Yue et al., households are more likely to change their risk behavior and become risk-averse. Further, COVID-19 increases the probability that a household will change its investment portfolio. [11]

Sreelakshmi and Prathap state that shifting to mobile-based banking transactions from physical banking transactions can be considered as a social distancing mechanism, which helps to prevent the spread of COVID-19 virus. As the spread of COVID-19 is expected to continue for long, the continued usage of mobile-based payment services as a strategy to maintain social distancing has to prevail. [12]

The study of Laguna et al. describes the impact of the COVID-19 health crisis on people's interests, opinions, and behaviour towards food. The answers to the online questionnaire showed reduction of shopping frequency but no changes in shopping location. Products purchased with higher frequency were pasta and vegetables (health motivations), others were purchased to improve their mood (nuts, cheese, and chocolates). Reduced purchasing was attributed to products with a short shelf-life (fish, seafood) or because they were unhealthy and contributed to gained body weight (sugary bakery goods) or mood (desserts). Statements made by experts or scientists were considered by consumers to be the most reliable. [13]

In scope of above mentioned, it has been formulated these hypotheses:

- COVID-19 pandemic has an impact on the perception of consumption and saving.

- COVID-19 pandemic has an impact on preference of cash less systems from consumer perspective

- COVID-19 pandemic has not got an impact on the philosophy of personal alimentation.

\section{Methodology}

The basic research problem has been insufficient knowledge about consumer behaviour on vending market in specific conditions of Slovak republic. The survey has been conducted in April and September 2020 via electronic tools of distribution as the contemporary pandemic situation didn't allow personal distribution of the questionnaire. Standardized method of the direct questioning via semi-structured written questionnaire has been used. We have realized this research via questionnaire survey in the form of computer assisted web interviewing respecting the ICC/ESOMAR International code on Market, Opinion and Social Research and Data Analytics.

A basic set of surveyed respondents has been composed by Slovak citizens older than 15 years (depending on the size of the basic set, the survey sample was 384 respondents). That age limit was set as it is the age when the legal subjectivity for labour is acquired 
according to a valid Slovak law. [14] However, one of the limitations of general applicability of the research outcomes has been caused by this fact - i.e. territorial applicability of the recommendations done on the basis of research outcomes only in scope of Slovak consumer's preferences. Thus, possible implementations of statements which result from own research are applicable only in case of alimentary goods brands addressed to Slovak consumer (domestic or foreign).

Hypotheses were tested using binomial test which uses the binomial distribution to decide if the outcome of an experiment in which we count the number of times one of two alternatives has occurred. $[15,16]$

\section{Results and discussion}

We verified hypothesis $\mathrm{H} 1$ using the binominal test. This test serves to reject or accept the null hypothesis $\mathrm{HO}$.

- Hypothesis $\mathrm{H}_{0}$ : COVID-19 pandemic has not got an impact on the perception of consumption and saving.

- Hypothesis $\mathrm{H}_{1}$ : COVID-19 pandemic has an impact on the perception of consumption and saving.

The value of testing characteristic was calculated $(6,2384)$. The critical testing characteristic was calculated through the Microsoft Excel, using the function NORMINV $(0,05 ; 0 ; 1)$. The resulting value was $-1,142\left(\mathrm{t}_{\mathrm{k}}\right)$. To accept the null hypothesis $\left(\mathrm{H}_{0}\right)$ which is the object of verification, the " $t$ " value has to be minor than " $t_{k}$ " value. As the " $t_{k}$ " value is minor than " $t$ " value $(6,2384>-1,142)$, the null hypothesis $\left(\mathrm{H}_{0}\right)$ is rejected and we accept the alternative hypothesis $\left(\mathrm{H}_{1}\right)$ at the significance level of 0,05 .

Thus, we can conclude that COVID-19 pandemic has an impact on the perception of consumption and saving.

The verification of hypothesis $\mathrm{H} 2$ was also based on the binominal test usage. This test served to reject or accept the so called null hypothesis $\mathrm{H}_{0}$.

- Hypothesis $\mathrm{H}_{0}$ : COVID-19 pandemic has not got an impact on preference of cash less systems from consumer perspective.

- Hypothesis $\mathrm{H}_{1}$ : COVID-19 pandemic has an impact on preference of cash less systems from consumer perspective.

The value of testing characteristic was calculated $(-1,091)$. The critical testing characteristic was calculated through the Microsoft Excel, using the function NORMINV $(0,05 ; 0 ; 1)$. The resulting value was $-1,623\left(\mathrm{t}_{\mathrm{k}}\right)$. To accept the null hypothesis $\left(\mathrm{H}_{0}\right)$ which is the object of verification, the " $t$ " value has to be minor than " $t_{k}$ " value. As the " $t_{k}$ " value is mayor than "t" value $(-1,623<-1,091)$, we can accept null hypothesis $\left(\mathrm{H}_{0}\right)$ and rejected the alternative hypothesis $\left(\mathrm{H}_{1}\right)$ at the significance level of 0,05 .

Thus, we can conclude that COVID-19 pandemic has not got an impact on preference of cash less systems from consumer perspective.

The verification of hypothesis $\mathrm{H} 3$ was also based on the binominal test usage. This test served to reject or accept the so called null hypothesis $\mathrm{H}_{0}$.

- Hypothesis $\mathrm{H}_{0}$ : COVID-19 pandemic has not got an impact on the philosophy of personal alimentation.

- Hypothesis $\mathrm{H}_{1}$ : COVID-19 pandemic has an impact on the philosophy of personal alimentation.

The value of testing characteristic was calculated $(3,814)$. The critical testing characteristic was calculated through the Microsoft Excel, using the function NORMINV $(0,05 ; 0 ; 1)$. The resulting value was $-1,002\left(\mathrm{t}_{\mathrm{k}}\right)$. To accept the null hypothesis $\left(\mathrm{H}_{0}\right)$ which is the object of verification, the " $\mathrm{t}$ " value has to be minor than " $\mathrm{t}_{\mathrm{k}}$ " value. As the " $\mathrm{t}_{\mathrm{k}}$ " value is 
minor than "t" value $(3,814>-1,002)$, the null hypothesis $\left(\mathrm{H}_{0}\right)$ is rejected and we accept the alternative hypothesis $\left(\mathrm{H}_{1}\right)$ at the significance level of 0,05 .

Thus, we can conclude that COVID-19 pandemic has an impact on the philosophy of personal alimentation.

Originally, it has been assumed, that COVID-19 pandemic would have significant impact on all analyzed perspectives of consumer behavior. $[11,12,13]$ This assumption has been verified only in case of the perception of consumption and saving and the philosophy of personal alimentation. However, in case of preference of cash less systems from consumer perspective it has not been proven the impact of the COVID-19 pandemic when survey results are take into account generally. On the other hand, when applying selective approach and comparing results which were obtained in April and September 2020, the trend of positive attitude towards cash less payment could be observed. Thus, it can be concluded, that cash less payments are very slowly going to be preferred by consumers. When analysing the reason of such a phenomenon, it can be stated, that the most relevant is social distancing mechanism, which helps to prevent the spread of COVID-19 virus. [7, 9] This fact is in contrast with generally stated trend of tendency towards implementation of progressive payment systems. On the example of this discrepancy between global trend on vending market and Slovak reality from the prospective of consumers, it can be highlighted the need of constructive criticism of implemented progressive patterns. It is because prospective investments to the progressive payment tools wouldn't be effective despite general practice on vending market would highly recommend it. Similarly it is also in case of change in philosophy of personal alimentation. Respondents have indicated that their positive attitude towards healthy goods has been caused mainly by their effort to protect the health and stimulate immunity in the era of COVID-19 pandemic.

\section{Conclusion}

The aim of the paper was to identify changes in consumer behaviour caused by Corona pandemic crisis in relevant industry of national economy. It has been fulfilled by applying comparative analysis on the case study of vending industry provided on chronological basis by double questionnaire at the beginning of the pandemic in Europe and after almost six months when it faces to the expected second wave. Based on the findings from own research, it has been possible to identify future trends in purchasing behaviour not only in case of chosen industry but also generally. These have been mainly the preference of cash less payment, the change in philosophy of personal alimentation and the shift in perception of consumption and savings.

This paper is an outcome of the science project VEGA no. 1/0064/20: Behaviorism in a socially responsible communication strategy of enterprises.

\section{References}

1. Grand View Research. (2019, August). Vending machine market size, share \& trends analysis report by application (offices, commercial places), by payment mode (cashless, cash), by region (MEA, APAC, North America), and segment forecasts, 2019 - 2025. Retrieved from : https://www.grandviewresearch.com/industry-analysis/globalvending-machine-market 
2. Fact.MR. (2020, May). Vending machines market forecast, trend analysis \& competition tracking - Global market insights 2020 to 2030. Retrieved from: https://www.factmr.com/report/4807/vending-machines-market

3. BusinessWire. (2020, July 22). Global vending machines market growth assessment Expected to reach $\$ 146.6$ billion by 2027, from an estimated \$134.4 billion in 2020 ResearchAndMarkets.com. Retrieved from: https://www.businesswire.com/news/home/20200722005591/en/Global-VendingMachines-Market-Growth-Assessment---Expected-to-Reach-146.6-Billion-by-2027from-an-Estimated-134.4-Billion-in-2020---ResearchAndMarkets.com

4. Assaf, A., Scuderi, R. (2020). COVID-19 and the recovery of the tourism industry. Tourism Economics, 26(5), 731-733.

5. Higgins-Desbiolles, F. (2020). The "war over tourism": Challenges to sustainable tourism in the tourism academy after COVID-19. Journal of Sustainable Tourism, early access: AUG 2020.

6. Raposo, A., Carrascosa, C., Perez, E., Saavedra, P., Sanjuan, E., Millan, R. (2015). Vending machines: Food safety and quality assessment focused on food handlers and the variables involved in the industry. Food Control, 56, 177-185.

7. Nadanyiova, M. (2017). Neuromarketing - An opportunity or a threat? Communications: Scientific Letters of the University of Žilina, 19(4), 90-94.

8. Stofkova, Z., Sukalova, V. (2020). Sustainable development of human resources in globalization period. Sustainability, 12(18), 7681.

9. Atwell, G.J., Lazaroiu, G. (2019). Are autonomous vehicles only a technological step? The sustainable deployment of self-driving cars on public roads. Contemporary Readings in Law and Social Justice, 11(2), 22-28.

10. Trettin, C., Lazaroiu, G., Grecu, I., Grecu, G. (2019). The social sustainability of citizen-centered urban governance networks: Sensor-based big data applications and real-time decision-making. Geopolitics, History, and International Relations, 11(2), 27-33.

11. Yue, P.P., Zhou, H.G. (2020). Household financial decision making amidst the COVID-19 pandemic. Emerging Markets Finance and Trade, 56(10), 2363-2377.

12. Laguna, L., Fiszman, S., Puerta, P., Chaya, C., Tarrega, A. (2020). The impact of COVID-19 lockdown on food priorities. Results from a preliminary study using social media and an online survey with Spanish consumers. Food Quality and Preference, 86, 104028.

13. Sreelakshmi, C.C., Prathap, Sangeetha K. (2020). Continuance adoption of mobilebased payments in Covid-19 context: an integrated framework of health belief model and expectation confirmation model. International Journal of Pervasive Computing and Communications, early Access: JUL 2020.

14. Gajanova, L., Nadanyiova, M. (2020). Specifics in brand value sources of customers in the banking industry from the psychographic point of view. Central European Business Review, 9(2), 1-18.

15. Krizanova, A., Gajanova, L., Nadanyiova, M. (2019). Design of a CRM level and performance measurement model. Sustainability, 10(7), 2567.

16. Borisova, V.V., Demkina, O.V., Mikhailova, A.V., Zielinski, R. (2019). The enterprise management system: Evaluating the use of information technology and information systems. Polish Journal of Management Studies, 20(1), 103-118. 